\title{
Pleomorphic Adenoma
}

National Cancer Institute

\section{Source}

National Cancer Institute. Pleomorphic Adenoma. NCI Thesaurus. Code C8602.

A neoplasm characterized by the presence of benign epithelial and myoepithelial cells and a mesenchymal component that may contain mucoid, myxoid, cartilaginous, or osseous areas. It may be completely or partially encapsulated. It occurs in the parotid gland, submandibular gland, minor salivary glands in the oral cavity, upper respiratory tract, and nasal cavity and paranasal sinuses. It usually presents as a slow growing painless mass. Infrequently, patients may present with pain and facial palsy. It may recur after excision or transform to a malignant neoplasm (carcinoma ex pleomorphic adenoma). 